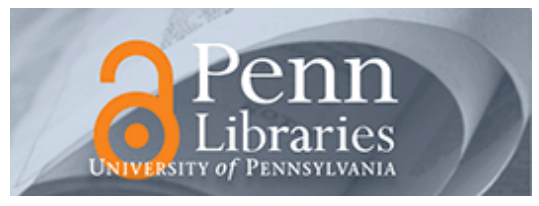

University of Pennsylvania

ScholarlyCommons

Marketing Papers

Wharton Faculty Research

$7-2015$

\title{
Looking for My Self: Identity-Driven Attention Allocation
}

Nicole V. Coleman

Patti Williams

University of Pennsylvania

Follow this and additional works at: https://repository.upenn.edu/marketing_papers

Part of the Cognition and Perception Commons, Cognitive Psychology Commons, Marketing Commons, Personality and Social Contexts Commons, and the Social Psychology Commons

Recommended Citation

Coleman, N. V., \& Williams, P. (2015). Looking for My Self: Identity-Driven Attention Allocation. Journal of Consumer Psychology, 25 (3), 504-511. http://dx.doi.org/10.1016/j.jcps.2015.01.001

This paper is posted at ScholarlyCommons. https://repository.upenn.edu/marketing_papers/363

For more information, please contact repository@pobox.upenn.edu. 


\title{
Looking for My Self: Identity-Driven Attention Allocation
}

\begin{abstract}
This research builds on the motivational aspects of identity salience, finding that social identities direct the allocation of attention in identity-syntonic ways. Drawing from identity-based motivation (Oyserman, 2009; Reed, et al., 2012) we suggest individuals use attention to enhance identity-fit; selectively focusing on cues and stimuli that are identity-consistent. In two studies we find that activating a social identity drives preferential attention toward identity-relevant stimuli. Using a novel paradigm, Study 1 demonstrates that individuals strategically focus attention on identity-consistent emotional stimuli, while also shifting attention away from identity-inconsistent emotional stimuli. Using a dot-probe paradigm, Study 2 extends these results to show that individuals allocate attention toward both emotional and non-emotional (semantic associates) stimuli that are identity-consistent, and away from those that are incompatible. Consistent with theories suggesting cognition and perception are constructed (James, 1890/1983) and that identities direct and influence meaning-making (Oyserman, 2009; Reed et al., 2012), we find that social identities drive attention allocation, with identity-consistent stimuli receiving greater attention; suggesting that an identity's sense-making begins with motivated attention toward perceiving an identity-consistent environment.
\end{abstract}

\section{Keywords}

social identity, attention, emotion

Disciplines

Business | Cognition and Perception | Cognitive Psychology | Marketing | Personality and Social Contexts | Social Psychology 
Looking for My Self: Identity-Driven Attention Allocation

Nicole Verrochi Coleman

University of Pittsburgh

Patti Williams

University of Pennsylvania

Conditionally Accepted, Journal of Consumer Psychology

\begin{abstract}
Author Note
Nicole Verrochi Coleman (ncoleman@katz.pitt.edu) is Assistant Professor of Business Administration, in the Marketing and Business Economics group, Katz GSB, University of Pittsburgh. Patti Williams (pattiw@wharton.upenn.edu) is Ira A. Lipman Associate Professor of Marketing, The Wharton School, University of Pennsylvania. The authors thank Shawn Zamechek for his fantastic programming work, and the Wharton Behavioral Laboratory for data collection assistance. Correspondence concerning this paper should be addressed to Nicole Verrochi Coleman, 382C Mervis Hall, University of Pittsburgh, Pittsburgh, PA 15260.
\end{abstract}




\begin{abstract}
This research builds on the motivational aspects of identity salience, finding that social identities can direct the allocation of attention in ways that are identity-syntonic. Drawing from identity-based motivation (Oyserman, 2009; Reed et al., 2012) we suggest individuals use attention to enhance identity-fit; selectively focusing on cues and stimuli that are identityconsistent. In two studies we find that activating a social identity drives preferential attention toward identity-relevant emotional stimuli. Study 1 demonstrates that individuals focus attention on identity-consistent stimuli, while also shifting attention away from stimuli that are identityinconsistent. Study 2 finds this process can be strategic, as attention shifts occur when the individual anticipates a stimulus that is identity-consistent (inconsistent). Thus, accordant with theories that suggest cognition and perception are constructed (James, 1890/1983) and that identities direct and influence meaning-making (Oyserman, 2009; Reed et al. 2012), we find that social identities drive consumers' attention allocation, with identity-consistent stimuli receiving greater attention; suggesting that an identity's sense-making begins with motivated attention toward perceiving an identity-consistent environment.
\end{abstract}

Keywords: Social identity, attention, emotion 
"Suffice it meanwhile that each of us literally chooses, by his ways of attending to things, what sort of a universe he shall appear to himself to inhabit." William James (1890/1983)

Imagine a football team, headed to a game. Along the highway they pass a billboard for a local soup kitchen, with a crying child imploring their help—will the players notice that ad? What if the child is holding a football? Attention is critical to the processing of information (Greenwald \& Leavitt, 1984), and emotion development and management (Gross, 1998). We explore whether aspects of a person's self—her active social identity—will prompt attention allocation to support that self-structure. As identities motivate sense-making (Oyserman, 2009), we propose a motivational account of attention allocation; active social identities will direct consumers' attention toward stimuli that support those identities. Additionally, we leverage work connecting social identities to discrete emotions (Coleman \& Williams, 2013), and find that attention is used enhance consistency between active social identities and emotional experiences.

Building on identity-based motivation (Oyserman, 2009; Reed, Forehand, Puntoni, \& Warlop 2012) we suggest individuals use attention to enhance identity-fit; selectively focusing on cues and stimuli that are identity-syntonic. Activating a social identity should drive preferential attention toward identity-relevant stimuli, cues, and emotions, as the individual reinforces the active identity (Reed et al., 2012). We find social identities drive consumers' attention allocation processes, with identity-consistent stimuli receiving greater attention; suggesting that an identity's sense-making begins with motivated attention toward perceiving an identity-relevant environment.

\section{Social Identities and Motivated Attention}


Individuals possess multiple social identities, varying in salience and centrality, derived from membership in social groups (Kleine, Kleine, \& Kernan, 1993; Reed, 2004; Tajfel, 1978). Attitudes, behaviors, and brands that assist in enacting a specific identity become associated with it, subsumed into its knowledge structure, providing guidance for expressing the identity (Kleine et al., 1993). Identities potentiate a readiness to make sense of the world and behave in an identity-congruent manner (Oyserman, 2009). When a specific identity is active, an individual views the world through that knowledge structure - avoiding identity-inconsistent activities and objects (Berger \& Heath, 2007), and approaching those that are consistent (Reed, 2004). Individuals rely on social identities to provide self-regulation that calibrates attitudes, values, and behaviors according to active identity standards (Oyserman, 2009; Reed et al., 2012).

Identities thus contain "what-to-do" information, enhancing the desirability of identityrelevant attitudes, behaviors, and objects (Reed et al., 2012). Recent work has also suggested that identities contain "what-to-feel" information; associations to specific discrete emotions may exist within an identity's knowledge structure, leading consumers to seek out, experience, and manage emotional experiences to maintain identity-consistency (Coleman \& Williams, 2013). Because discrete emotions imply unique action tendencies (Frijda, 1986) and identities also potentiate actions (Oyserman, 2009), certain emotions may be relevant to the goals and objectives of specific social identities, becoming linked to identity-relevant action readiness. Following this, we focus on attention allocated to identity-relevant emotions, and consider how attention may be used to enhance identity-fit.

Attention is a basic cognitive process; the situational elements that receive attention define perception (Erdelyi, 1974; Posner \& Petersen, 1990; Treisman, 2006). Whether invoked automatically or consciously, attention processes are the primary perceptual gatekeeper, through 
which information is sorted, managed, and evaluated (Erdelyi, 1974). Given limited resources and a potentially overwhelming amount of stimuli, individuals strategically allocate perceptual resources, scanning the environment to determine which receive further attention (Gray, Ambady, Lowenthal, \& Deldin, 2004). While some stimuli may have an evolutionary "default" demand on attention (Öhman et al., 2001; Tooby \& Cosmides, 1990), cognition is in the service of doing (James 1890/1983); individuals selectively allocate cognitive resources, focusing attention according to their interests, needs, values, desires, and goals (Balcetis \& Dunning, 2006; Bargh, 1982; Folk, Remington, \& Johnston, 1992; Pieters \& Wedel, 2007). Self-relevance is thus a critical determinant in what stimuli require further resources; information related to the self (e.g., one's name), personal values, and concerns is given preferential attention (Bargh, 1982; Moray, 1959). Though extant research has not examined the implications of an active social identity on the allocation of attention to identity-relevant stimuli, Oyserman (2009) argued that identities activate broad-based motivations to engage in identity-congruent actions and to use identity-congruent mindsets to understand the world. This procedural readiness prompts sense-making, providing a lens for attending to and interpreting the social environment, potentiating processes and actions that enhance identity-fit (Oyserman, 2009).

Consistent with the perspective that attention is allocated in self-relevant ways and that social identities are important self-structures which provide a lens for cognition, we propose that identity-based motivation will drive changes in attention allocation, causing consumers to allocate greater attention to stimuli that support their active identity, while reducing attention toward identity-inconsistent stimuli. In addition, building upon Coleman and Williams (2013), we focus upon identity-based allocation of attention resources to emotional stimuli that are consistent with a salient social identity. We examine these attention processes in two studies, 
using two common social identities: athlete and volunteer, and their relevant negative emotions, anger and sadness (Coleman \& Williams, 2013). Anger is likely associated with the athlete identity because its external locus of control emphasizes obstacles impeding goal pursuit, inspiring the desire to overcome barriers (Frijda, 1986). Sadness is likely associated with volunteers because it indicates a need for help (Izard, 1977) and promotes feelings of sympathy and willingness to behave prosocially (Small \& Verrochi, 2009). Though positive emotions may also be associated with social identities, they tend to lack specific action tendencies (Frijda, 1986), are more diffuse, and may be relevant to many identities. Study one provides evidence for identity-based attention allocation; participants focus attention on identity-consistent stimuli, and divert attention away from identity-inconsistent ones. Study two demonstrates strategic, anticipatory, attention allocation toward consistent and away from inconsistent stimuli as individuals respond to warning cues about upcoming stimuli and subsequently deploy attention in anticipation of these identity-relevant events.

\section{Study 1: Identity-Fit Drives Attention Allocation}

We activate two social identities (athlete and volunteer) and examine attention toward identity-relevant emotion cues (anger and sadness; Coleman and Williams 2013). Given associations previously identified between these identities and emotions, we anticipate participants with an active athlete identity should selectively focus on anger-related stimuli, avoiding sadness-related cues, while the reverse should be true for volunteers. We use a visual probe paradigm to measure selective attention (MacLeod \& Mathews, 1988; MacLeod, Mathews, \& Tata 1986).

\section{Procedure and Design}


Students and staff $(\mathrm{N}=176 ; 59 \%$ female; average age 26 , range $18-70)$ at a northeastern university participated, during an hour-long experimental session, receiving $\$ 10$. They completed two "unrelated" tasks: a writing task (identity prime) and an attention task (visual probe). First, participants wrote for 5 minutes about a specific time when they performed as an athlete or a volunteer or what they did the previous day (control), and then listed 3-10 things they could do to demonstrate they are an athlete/volunteer or their plans for tomorrow (Reed 2004).

The second task measured attention toward and away from stimuli (MacLeod \& Mathews, 1988; MacLeod et al., 1986). This visual probe task involves participants responding to a neutral stimulus (dot) following the presentation of stimulus pairs (words). First, two words are presented simultaneously on-screen, side-by-side. Attention is measured by a secondary stimulus, whereby participants indicate the location of a small dot, which could appear in the location of either word, immediately after both words disappear from the screen. Response latencies for probes in each location (left vs. right) reveal attention allocation across the two locations; participants are slower to locate a dot if they had deployed attention to the word other position (away from where the dot appears). For example, a participant with an active athlete identity might see an identity-consistent word pair (e.g., enraged + balloon). The dot might then appear behind the neutral word (balloon). If so, the participant should be slower to respond to the dot's location because we anticipate he would have allocated his attention toward the anger word (enraged). However, if the participant saw an identity-inconsistent pair (e.g., grief + fudge) and the dot appeared behind the neutral word, we would expect him to be faster to respond; evidence that he focused away from the inconsistent stimulus (grief) and onto the neutral location (fudge). Thus, by presenting words in pairs we can assess whether participants are allocating attention to an emotional stimulus or away from it in ways that are identity-consistent. 
Stimuli. Three sets of words were developed for the tests: anger-related words, sadnessrelated words, and neutral words. An initial set of 24 words of each emotion type, and 200 neutral words were pretested online by 100 individuals. Each participant rated 40 randomly selected words on how angry, sad, neutral, and familiar each was on 7-point scales $(1=$ not at all, $7=$ extremely). On the basis of these ratings, 12 anger words, 12 sad words, and 96 neutral words, matched for familiarity and length, were selected (Table 1).

Insert table 1 about here

Each emotion word was paired with a neutral word, to make 24 critical emotion pairs; 48 neutral-only word pairs were used as fillers. Critical pairs thus contained one emotion word and one neutral word; no pairs contained two emotion words. Each pair was presented for $1500 \mathrm{ms,}$ separated by a horizontal distance of 3 inches (from MacLeod et al., 1986). Following wordpairs, a small dot appeared in the same location as one of the two words and remained on screen until participants indicated whether it was on the left (z-key) or right (m-key). The program recorded the response (left/right) and response latency. A fixation point was presented for 1500 ms between each trial. Within the 72 trials, 24 contained a critical pair, and are the trials of interest. The location of the emotion word within the pair (left/right side) was determined randomly, as was the subsequent dot position.

Thus, this is a 3 identity (athlete, volunteer, control) by 2 word type (anger, sadness) by 2 probe position (behind emotion, behind neutral) mixed design; social identity was betweensubjects, while word type and probe position were within-subjects. Attention allocation for identity-fit will result in an interaction of word type and probe position. We predict that this interaction will depend on participants' active identity, evidenced by focusing on identity- 
consistent words. Athlete identity participants should allocate attention toward anger-related words; faster responses when the dot is located behind anger words, and slower responses when the dot is away from the anger location. Volunteers should show faster responses when the dot is located behind sad words, but slower times when the dot is behind the neutral word in a sad pair. We also anticipate individuals will divert attention away from identity-inconsistent words: athletes should show slower reaction times when the dot is in the same location as a sad word, and faster times when the dot is behind the neutral word in a sad-neutral pair. Volunteers should divert attention by responding more slowly when the dot is co-located with anger words and more quickly when the dot is behind the neutral word in an anger-neutral pair.

\section{Results}

Analyses were run on log-transformed RTs for correct responses only (error rate: $0.5 \%$; Ferguson, 2007; MacLeod \& Mathews, 1988). For explication, Figure 1 and reported means are untransformed. The RTs by word type (averaged across the 12 angry and 12 sad trials) were entered into a repeated-measures ANOVA with word type (angry, sad) and probe position (behind emotion, behind neutral) as within-subject variables and identity (athlete, volunteer, control) between-subjects. No significant main effects were found, however a significant twoway interaction of word type and probe position emerged, $(F(1,173)=11.474, p=.001)$. This two-way interaction was subsumed within the predicted three-way interaction $(F(2,173)=$ $42.892, p<.0001)$.

Insert figure 2 about here

The three-way interaction was reduced using the Tukey Test to perform individual mean comparisons. This analysis revealed that while there were marginally significant differences in 
reaction times in the control condition $(p s>.08)$, participants with active athlete or volunteer identities showed a marked slowing in responses both when the probe was behind the neutral word on an identity-consistent trial, and when the probe was located behind an identityinconsistent emotion word. Participants with an active athlete identity were slower on anger trials when the dot was behind neutral words $(M=447.74)$ than behind anger $(M=428.31 ; \mathrm{t}(63)=$ 3.202, $p=.002$ ), implying that their attention was directed toward anger words, requiring them to shift attention to locate the dot, slowing responses. On the other hand, on sad trials, athletes were slower to respond when the dot was located behind sad words $(M=452.43)$ than behind neutral $\left(M_{1}=430.69 ; t(63)=-3.181, p=.002\right)$. This suggests they directed attention away from identityinconsistent (sad) stimuli, toward the neutral word, leading to longer response latencies. When the dot appeared behind an emotion word, participants with an active athlete identity were faster if it was behind an angry word than $\operatorname{sad}(t(63)=3.827, p<.001)$, but when it was behind a neutral word, were faster if it was paired with sad than with angry words $(t(63)=-2.620, p=$ $.011)$, indicating that athlete participants focused on anger words, but diverted away from sad words.

Participants with an active volunteer social identity showed the reverse. On anger trials, volunteers were slower to locate the dot when it was behind an anger word $(M=476.91)$ than behind neutral $(M=444.57 ; t(58)=-3.430, p=.001)$; implying attention directed away from anger stimuli. On the sad trials, volunteers were slower when the dot was behind the neutral word $(M=482.63)$ than behind $\operatorname{sad}(M=432.21 ; t(58)=5.563, p<.001)$, suggesting attention directed toward sad words. When the dot was behind the emotion word, volunteer identity participants responded faster when it was behind a sad word than angry $(t(58)=-4.278, p<$ 
$.001)$, but when it was behind a neutral word, were faster on angry trials than $\operatorname{sad}(t(58)=4.521$, $p<.001)$.

\section{Discussion}

Study 1 examines identity-driven allocation of attention to stimuli. Results demonstrate that social identities increase attention toward identity-consistent stimuli, but also that individuals allocate attention away from identity-inconsistent materials. Participants with an active athlete identity were fastest to detect probes behind anger words (identity-consistent targets) or a neutral word on a sad trial (away from identity-inconsistent targets). Participants with an active volunteer identity were fastest to detect probes behind sad words (identityconsistent targets) or neutral words on angry trials (distant from identity-inconsistent targets). Results suggest that social identity motivates attention allocation, such that participants direct attention toward identity-consistent and away from identity- inconsistent stimuli. Thus, attention is not only drawn toward stimuli congruent with an active identity, but away from incongruent materials — suggesting goal-directed attention not only increases processing of relevant information (Folk et al., 1992) but also reduces attention to inconsistent information. Study 2 explores this further, examining attention allocation and its strategic, anticipatory, deployment.

\section{Study 2: Strategic Attention Allocation for Identity-Consistency}

Study 2 demonstrates individuals engage in strategic, anticipatory, attention shifts toward (away from) emotional stimuli that are identity-consistent (inconsistent). We find that attention allocation can be strategic; when participants are warned about an upcoming emotional event, they preemptively allocate attention in preparation for that event, maintaining identity- 
consistency. To assess these differences in attention, a novel paradigm is developed, which measures both anticipatory and reactive attention allocation.

\section{Procedure and Design}

Participants completed a writing task (identity prime) and a perceptual task (attention measure). Participants were randomly assigned to complete one identity prime (athlete, volunteer) from study 1 (Reed, 2004) and then moved to the attention task (T Task), where they quickly and accurately identified whether the letter T was right-side up (z-key) or up-side down (m-key). This was difficult as the letter was small (3/4 inch), presented briefly (115 ms), and at low contrast ( $80 \%$ black letter on a $40 \%$ black background). For participants to accurately identify the $\mathrm{T}$ orientations, they must focus their attention. Thus, decreased accuracy indicates participants shifting attention away from the target location, while high accuracy demonstrates attention focused on the target location. Photographs were interspersed in the T task, providing the emotional stimuli. Two types of pictures were presented (all from the International Affective Picture System; Lang, Bradley, \& Cuthbert, 2005): mildly positive (e.g., flowers) and sad (e.g., crying children).

Importantly, pictures were preceded by a probabilistic cue (Figure 3). The 'sad' cue (red; 8 trials) indicated the upcoming picture would likely be sad: on 6 of the red cue trials the photo was sad, while 2 trials showed a positive photo. The 'positive' cue (green; 8 trials) indicated the picture would likely be positive ( 6 trials were positive photos, 2 were sad). Finally a 'control' cue (yellow; 8 trials) only indicated that a picture was upcoming, but gave no information of its emotion; 4 of the yellow cues preceded sad photos, the other 4 positive photos. These cues allowed participants to anticipate the upcoming picture type and deploy attention according to 
identity-fit; athletes wanting to avoid sad stimuli could shift attention away from the T location after a red cue.

\section{Insert figure 3 about here}

All negative pictures were sad; for athletes, sad emotions are identity-inconsistent, and should be avoided by shifting attention away from the target when they expect an inconsistent picture (red cue) and when they actually see a sad photograph. These shifts will manifest as lowered accuracy of T identification following red cues and sad pictures. In contrast, for volunteers, attention should not shift away from sad pictures, as sadness is identity-consistent. Thus, their accuracy should remain high following red cues and sad pictures.

Participants completed 24 trials, each featuring a series of Ts, interrupted by cues and pictures. The number and orientation of the Ts varied randomly to reduce trial predictability and maintain the cue's informational value. Within the task, participants could either focus attention on the Ts and the emotional photos or shift attention away from the Ts and photographs. Attention is measured by accuracy of the T orientation assessments following cues and the photographs: attention shifts lead to decreased performance.

The study is a mixed design with identity (athlete, volunteer) between-subjects, and cue (red, green, yellow) and picture (positive, sad) within-subjects. Attention allocation is assessed both following the cue and after the photograph. After seeing a cue (red, green or yellow), but before a picture is shown, we expect a two-way interaction between cue and identity: volunteers seeing a red cue should anticipate an identity-consistent sad photograph, keeping their attention focused on the T-location, resulting in accurate $\mathrm{T}$ assessments. However, athletes seeing a red cue should have reduced accuracy as they shift attention from the focal location. After seeing a 
photograph (sad or positive), we predict a three-way interaction: volunteer identity participants will remain focused on the target location, anticipating and experiencing an identity-consistent sad photograph, and thus show high accuracy. Athlete participants will shift attention away from red cues and sad pictures, leading to reduced accuracy. As positive emotions (e.g., happiness) are equally relevant for athletes and volunteers, we expect no accuracy differences following the green cues or positive photographs; finally, yellow cues allow us to examine the pure effect of the photograph, without anticipatory attention allocation.

\section{Participants and Procedure}

Students and staff $(\mathrm{N}=52 ; 56 \%$ female; average age 22 , range 18-63) at a northeastern university participated, during an hour-long experimental session, receiving \$10. Participants completed 24 trials: each consisted of T identifications (5-7 Ts), a cue (red, yellow, or green), more T identifications (3-5 Ts), a picture (positive or sad) and another set of T identifications (37 Ts). Afterwards, participants were debriefed and paid.

\section{Results}

Anticipatory Attention Shifts. A two-factor mixed ANOVA with identity betweensubjects and cue as a repeated measure was performed on average post-cue accuracy. There were no significant main effects, but a significant cue by identity interaction emerged $(F(4,48)=$ $5.121, p=.028)$. Contrasts show an active volunteer identity increased accuracy after a red cue $(M=89.0 \%)$ compared to green $(M=84.9 \% ; F(1,49)=4.109, p=.048)$. In the athlete condition accuracy was better following a green cue $(M=86.4 \%)$ than a red cue $(M=82.3 \% ; F(1,50)=$ $4.753, p=.034)$. Within the red cues, there was a significant difference between the volunteer $(M$ $=89.0 \%)$ and athlete identity $(M=82.3 \% ; F(1,50)=5.983, p=.018)$. Results demonstrate that an active identity led to strategically allocated attention in anticipation of the upcoming picture 
after receiving a cue about its identity relevance. This supports our theory that attention is used in service of identity goals, and shows that identity-based attention allocation can be forwardlooking.

Insert figure 4 about here

Reactive Attention Shifts. A three-way mixed repeated measure ANOVA was run on average accuracy in the post-picture period. A main effect of identity was significant $(F(1,50)=$ $5.676, p<.05)$; those with an active volunteer identity were more accurate $(M=86.3 \%)$ than athletes $(M=74.3 \%)$. No other main effects were significant. A significant interaction between identity and the cue emerged, $(F(2,48)=3.278, p=.042)$. Following a red cue, participants with active athlete identities performed significantly worse than volunteers $\left(M_{\text {athlete }}=64.6 \% \mathrm{vs}\right.$. $\left.M_{\text {volunteer }}=88.9 \% ; F(1,50)=8.579, p<.01\right)$. Performance was not different for the two identities following the green or yellow cues (both $p>.30)$.

\section{Insert figure 5 about here}

The predicted three-way interaction between identity, cue, and picture type emerged (Figure $5 ; F(2,48)=3.278, p=.046)$. Participants in the athlete condition who saw a positive picture preceded by a red cue, had poorer performance $(M=66.7 \%)$ than after positive pictures preceded by green cues $(M=84.8 \% ; F(2,49)=3.407, p<.05)$, and marginally so compared to yellow cues $(M=81.8 \% ; F(2,49)=2.671, p=.079)$. There was no difference between the green and yellow cues preceding positive pictures $(p>.60)$. However, when participants with active athlete identities saw a sad picture preceded by a red cue, performance declined $(M=62.5 \%)$ relative to sad pictures preceded by either green $(M=75.8 \% ; F(2,49)=3.315, p<.05)$ or 
yellow $(M=74.2 \% ; F(2,49)=3.292, p<.05)$ cues. These results suggest that athletes realized that red cues signaled an identity-inconsistent picture, and shifted attention away, decreasing accuracy.

Participants with active volunteer identities who saw a positive picture preceded by a red cue, showed increased accuracy relative to positive pictures preceded by a green cue $\left(M_{\text {red }}=\right.$ $94.7 \%$ vs. $\left.M_{\text {green }}=76.8 \% ; F(2,49)=4.175, p<.05\right)$. Performance after yellow cues $(M=$ $78.9 \%)$ did not differ from after red or green cues $(p s>.15)$. When volunteers saw a sad picture, it did not matter which color cue they had seen before it $\left(M_{\text {green }}=94.7 \%, M_{\text {red }}=83.2 \%, M_{\text {yellow }}=\right.$ $89.5 \%$; all $p>.20$ ). Results suggest those with salient volunteer identities did not see the red cues or sad pictures as emotional events to be avoided; as sadness is identity-consistent, they focused attention on the target location, resulting in high accuracy.

\section{Discussion}

Study 2 introduces a paradigm to measure attention and demonstrates that individuals can strategically allocate attention toward identity-consistent stimuli and away from inconsistent ones. Volunteer identity participants did not shift attention away from the red cues or sad pictures, but rather increased attention toward sad stimuli. In contrast, the athlete identity participants showed performance decrements following sad pictures and red cues, as they shifted their attention away from these stimuli to avoid sadness. Shifts were strategic in response to cues that helped participants form an expectation of the upcoming picture (identity-consistent or inconsistent). Evidenced by both the anticipatory and reactive attention allocation, this study demonstrates that active identities potentiate attention toward identity-consistent stimuli, and away from inconsistent environmental elements. 


\section{General Discussion}

Identity-based motivation potentiates procedures and actions that fit a salient identity (Oyserman, 2009). Thus, consumers often examine and understand the environment through an identity-specific lens (Kleine et al., 1993; Oyserman, 2009). The present research finds that identity-based motivation drives basic cognitive processes such as attention allocation, thereby mobilizing higher-order processing and subsequent behaviors. Two studies demonstrate that individuals allocate attention to enhance identity-fit. Study 1 showed that individuals are sensitive to identity-consistent stimuli, and that they shift attention away from stimuli that are identity-inconsistent. Study 2 found this process can be strategic, as attention shifts occur when the individual anticipates a stimulus that is identity-consistent (inconsistent).

Recent research has suggested discrete emotions are implicated within identity enactment (Coleman and Williams 2013); the present research offers further contributions. Emotions arise as a function of appraisal processes (Frijda, 1986; Larazus, 1991), wherein environmental stimuli are scanned for self-relevance. Our results suggest that individuals allocate attention toward the appraisal of identity-consistent emotional stimuli, thereby potentiating the experience of those emotions supporting identity-fit.

Marketers often try to capture consumers' attention, from packaging and end-cap displays (Drèze, Hoch, \& Park, 1993) to emotions in advertising (Heath, Brandt, \& Nairn, 2006). Selective attention can impact comprehension, preference formation, and subsequent product choice (Janiszewski, Kuo, \& Tavassoli, 2013). Our results suggest marketing stimuli possessing identity-relevant cues, including emotions, are more likely to break through the clutter, attracting consumer attention in ways that may lead to identity-syntonic consumption decisions. 
We examined only two social identities and one relevant emotion for each. Additional research should generalize these findings to other identities and emotions. Evidence that individuals shift attention away from identity-incongruent cues suggests future research. What might happen if individuals attend to identity-inconsistent emotions? Would attending to sadness create an identity-threat for athletes? Future research could examine whether identityinconsistent stimuli act as identity threats, and whether that encourages a vigilant mindset to protect against said threats.

This research builds on the motivational aspects of identity salience, finding that social identities can direct attention. Accordant with theories that suggest cognition and perception are constructed (James, 1890/1983), that meaning and understanding arise through interpreting meaningful features of the environment (Fiske, 1992), and that identities direct and influence meaning-making (Oyserman, 2009; Reed et al. 2012), we find that individuals strategically allocate attention in service of identity-fit. 


\section{References}

Balcetis, E. \& Dunning, D. (2006). See what you want to see: Motivational influences on visual perception. Journal of Personality and Social Psychology, 91 (4), 612-625.

Bargh, J.A., (1982). Attention and automaticity in processing of self-relevant information. Journal of Personality and Social Psychology, 43 (3), 425-436.

Berger, J. \& Heath, C. (2007). Where consumers diverge from others: Identity-signaling and product domains. Journal of Consumer Research, 34, 121-34.

Coleman, N. V. \& Williams, P. (2013). Feeling like my self: Emotion profiles and social identity. Journal of Consumer Research, 40, 203-222.

Drèze, X., Hoch, S.J., \& Park, M.E. (1993). Shelf management and space elasticity. Journal of Retailing, 70, 301-326.

Erdelyi, M. H. (1974). A new look at the new look: Perceptual defense and vigilance. Psychological Review, 81, 1-25.

Ferguson, M. J. (2007). On the automatic evaluation of end-states. Journal of Personality and Social Psychology, 92, 596-611.

Folk, C. L., Remington, R. W., \& Johnston, J. C. (1992). Involuntary covert orienting is contingent on attentional control settings. Journal of Experimental Psychology: Human Perception and Performance, 18, 1030-1044.

Fiske, A.P., (1992). The four elementary forms of sociality: Framework for a unified theory of social relations. Journal of Personality and Social Psychology, 99, 689-723.

Frijda, N. H. (1986). The emotions. New York, NY: Cambridge University Press.

Gray, H. M., Ambady, N., Lowenthal, W. T., \& Deldin, P. (2004). P300 as an index of attention to self-relevant stimuli. Journal of Experimental Social Psychology, 40, 216-224. 
Greenwald, A. G., \& Leavitt, C. (1984). Audience involvement in advertising: Four levels. Journal of Consumer Research, 11, 581-592.

Gross, J. J. (1998). Antecedent- and response-focused emotion regulation: Divergent consequences for experience, expression, and physiology. Journal of Personality and Social Psychology, 74, 224-237.

Heath, R., Brandt, D., \& Nairn, A. (2006). Brand relationships: Strengthened by emotion, weakened by attention. Journal of Advertising Research, 46, 410-419.

Izard, C. E. (1977). Human emotions. New York: Plenum.

James, W. (1890/1983). The principles of psychology. New York: Holt.

Janiszewski, C., Kuo, A., \& Tavassoli, N.T. (2013). The influence of selective attention and inattention to products on subsequent choice. Journal of Consumer Research, 39, 12581274.

Kleine R.E., III, Kleine, S. S., \& Kernan J.B. (1993). Mundane consumption and the self: A social identity perspective. Journal of Consumer Psychology, 2, 209-35.

Lang, P. J., Bradley, M. M., \& Cuthbert, B. N. (2005). International affective picture system (IAPS): Affective ratings of pictures and instruction manual. Technical Report A-6. Gainesville: University of Florida, Center for Research in Psychophysiology.

Lazarus, R.S. (1991). Progress on a cognitive-motivational-relational theory of emotion. American Psychologist, 46, 819-834.

MacLeod, C., \& Mathews, A. (1988). Anxiety and the allocation of attention to threat. Quarterly Journal of Experimental Psychology, 40, 653-670.

MacLeod, C., Mathews, A., \& Tata, P. (1986). Attentional bias in emotional disorders. Journal of Abnormal Psychology, 95, 15-20. 
Moray, N. (1959). Attention in dichotic listening: Affective cues and the influence of instructions. Quarterly Journal of Experimental Psychology, 34, 740-754.

Öhman, A., Flykt, A., \& Esteves, F. (2001). Emotion drives attention: Detecting the snake in the grass. Journal of Experimental Psychology: General, 130, 466-478.

Oyserman, D. (2009). Identity-based motivation and consumer behavior. Journal of Consumer Psychology, 19, 276-79.

Pieters, R. \& Wedel, M. (2007). Goal control of attention to advertising: The Yarbus implication. Journal of Consumer Research, 34, 224-233.

Posner, M. I. \& Peterson, S. E. (1990). The attention system of the human brain. Annual Review of Neuroscience, 13, 25-42.

Reed, A. II. (2004). Activating the self-importance of consumer selves: Exploring identity salience effects on judgments. Journal of Consumer Research, 31, 286-95.

Reed, A. II., Forehand, M.R., Puntoni, S., \& Warlop, L. (2012). Identity-based consumer behavior. International Journal of Research in Marketing, 29, 310-321.

Small, D. \& Verrochi, N. M. (2009). The face of need: Facial emotion expression on charity advertisements. Journal of Marketing Research, 46, 777-87.

Tajfel, H. (1978). Social categorization, social identity and social comparison. In H. Tajfel (Ed.), Differentiation Between Social Groups (pp. 61-76). New York, NY: Academic Press, Inc.

Tooby, J. \& Cosimides, L. (1990). The past explains the present. Emotional adaptations and the structure of ancestral environments. Ethology and Sociobiology, 11, 375-424.

Treisman, A. (2006). How the deployment of attention determines what we see. Visual Cognition, 14, 411-443. 


\section{Table 1}

Anger and Sadness Words Used In Study 1

\begin{tabular}{|r|l|l|}
\hline & \multicolumn{1}{|c|}{ Anger } & \multicolumn{1}{c|}{ Sadness } \\
\hline \hline 1 & mad & sad \\
2 & fury & blue \\
3 & angry & grief \\
4 & livid & upset \\
5 & bitchy & sorrow \\
6 & malice & lonely \\
7 & peeved & misery \\
8 & enraged & crushed \\
9 & hateful & despair \\
10 & hostile & unhappy \\
11 & outraged & dismayed \\
12 & frustrated & depressed \\
\hline
\end{tabular}


Figure 1

Study 1: Reaction Times in Dot-Probe Task Are Dependent On Both the Emotion Word and Active Social Identity

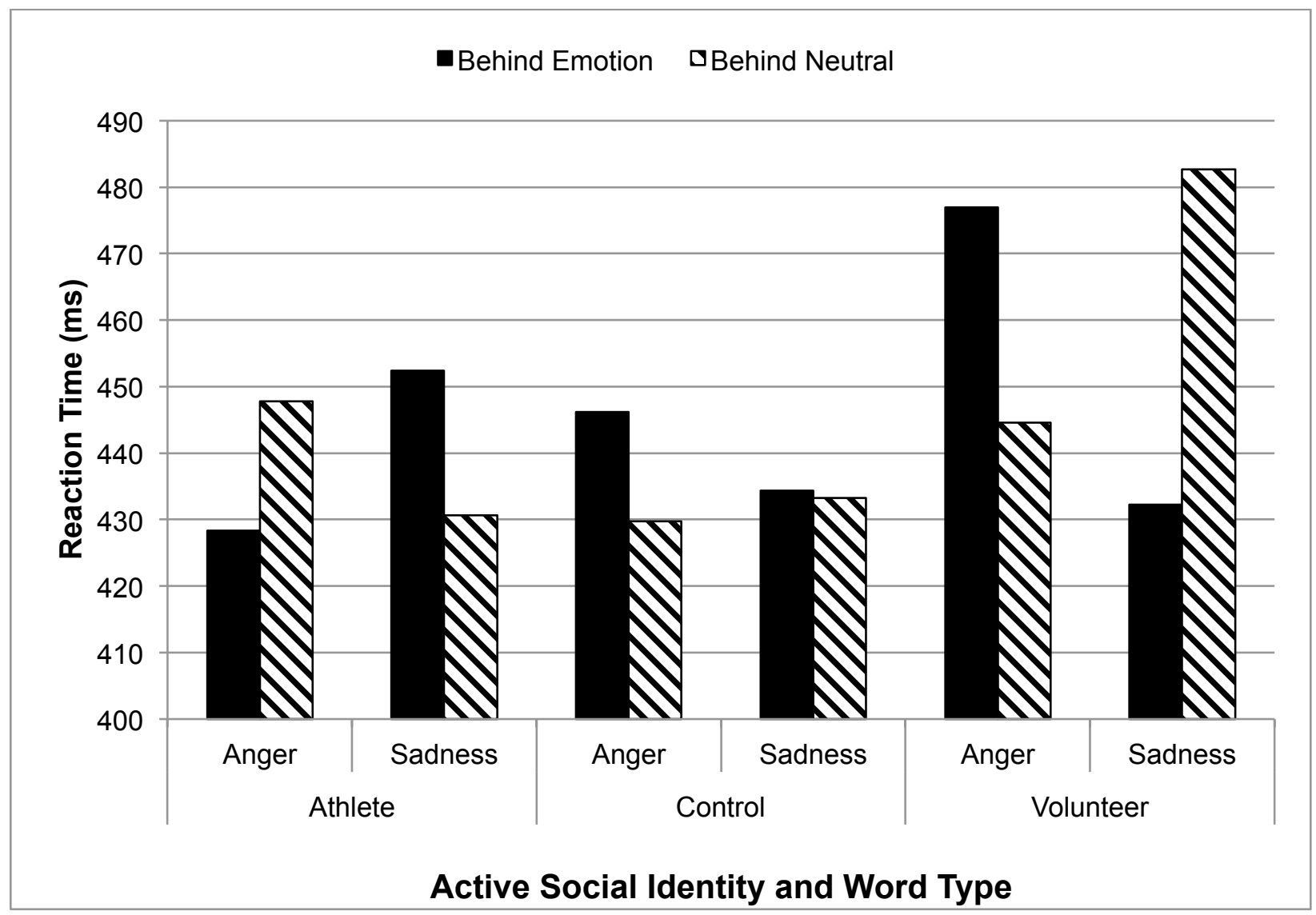

Note: cell sizes ranged from 52 to 63 in each identity condition. 
Figure 2

Study 2: Procedure

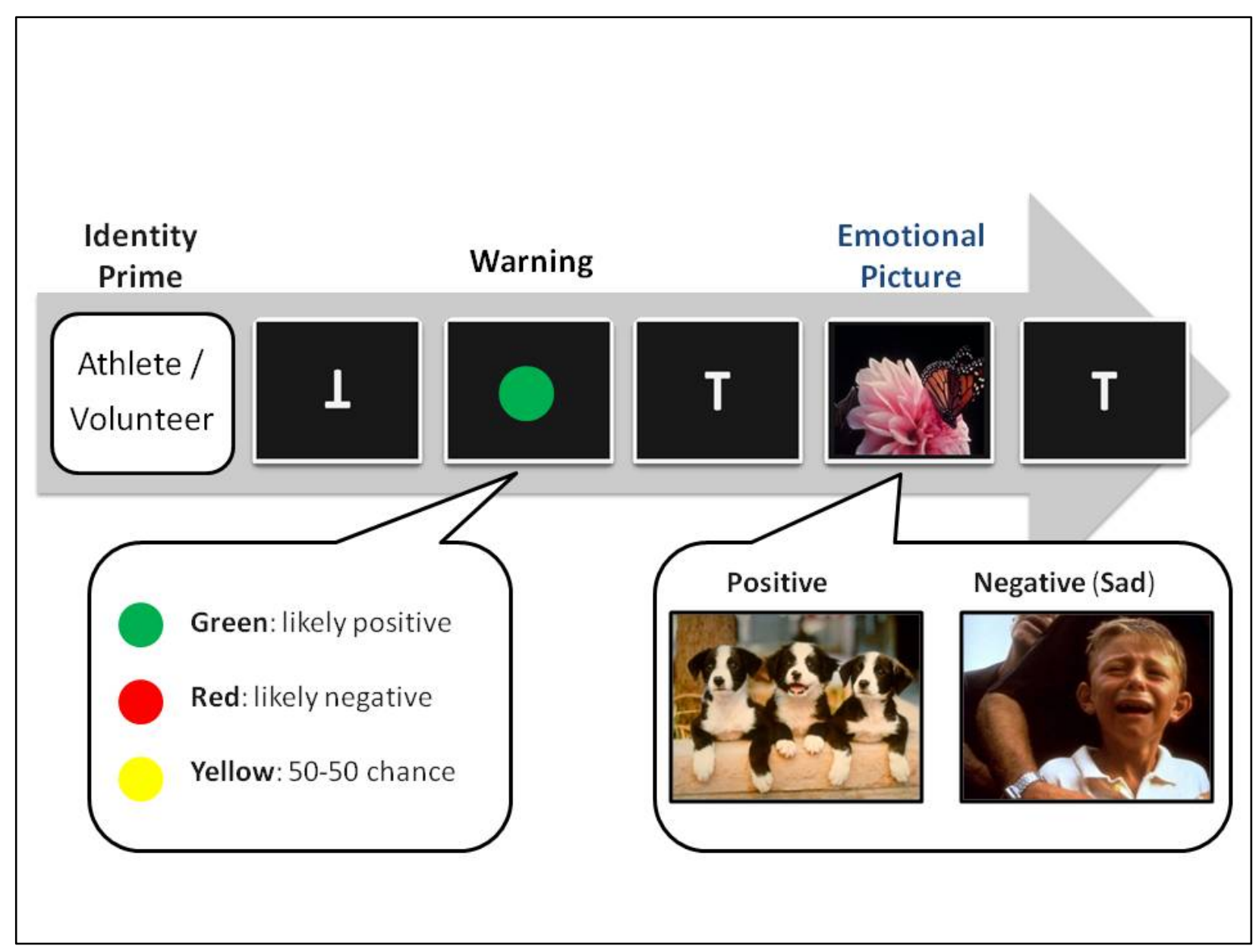


Figure 3

Study 2: Anticipatory Attention Allocation before Emotional Stimuli Presentation

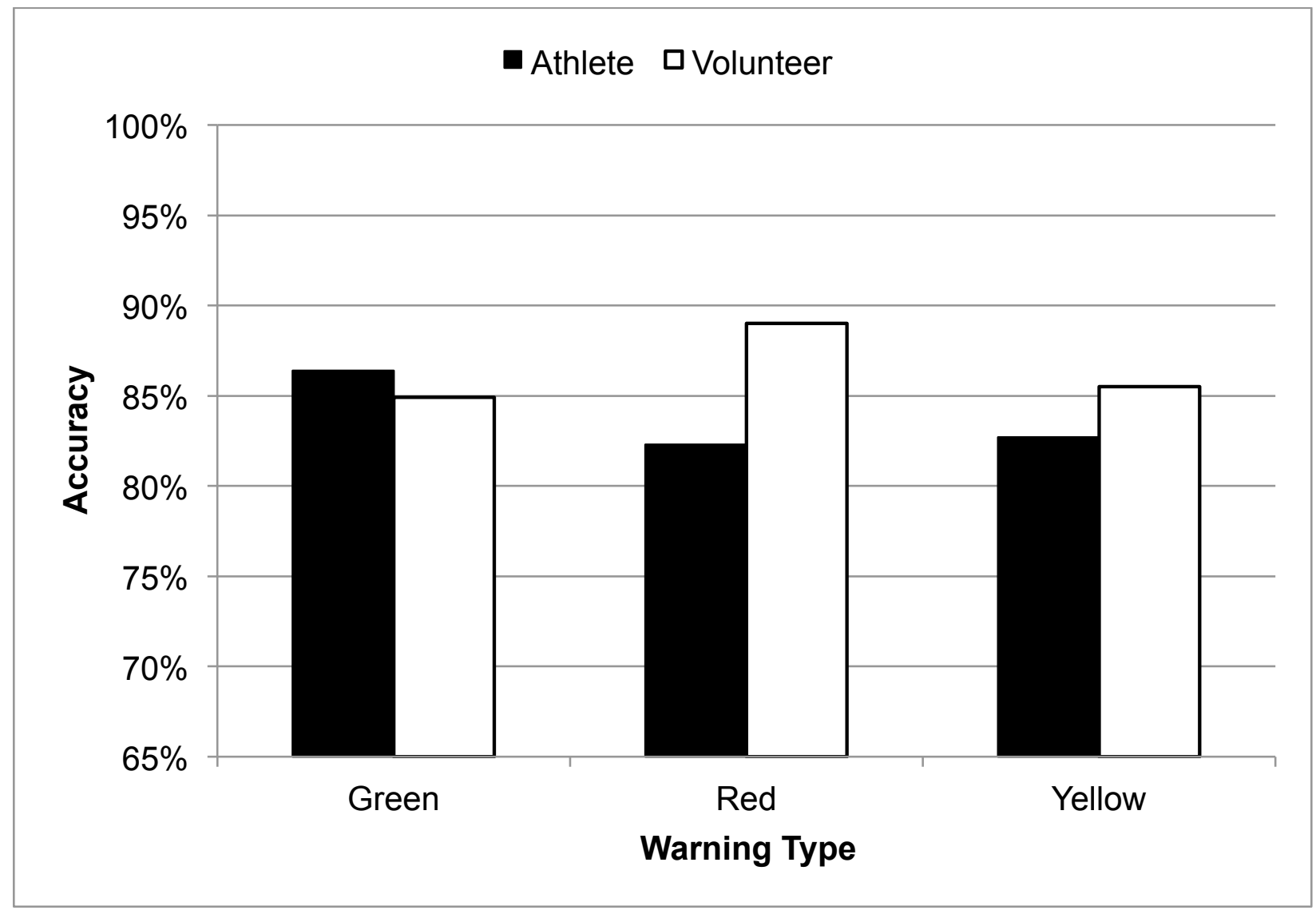

Note: There were 27 participants in the athlete condition and 25 in the volunteer condition. 
Figure 4

Study 2: Strategic Attention Allocation toward Emotion Profile-Consistent Stimuli
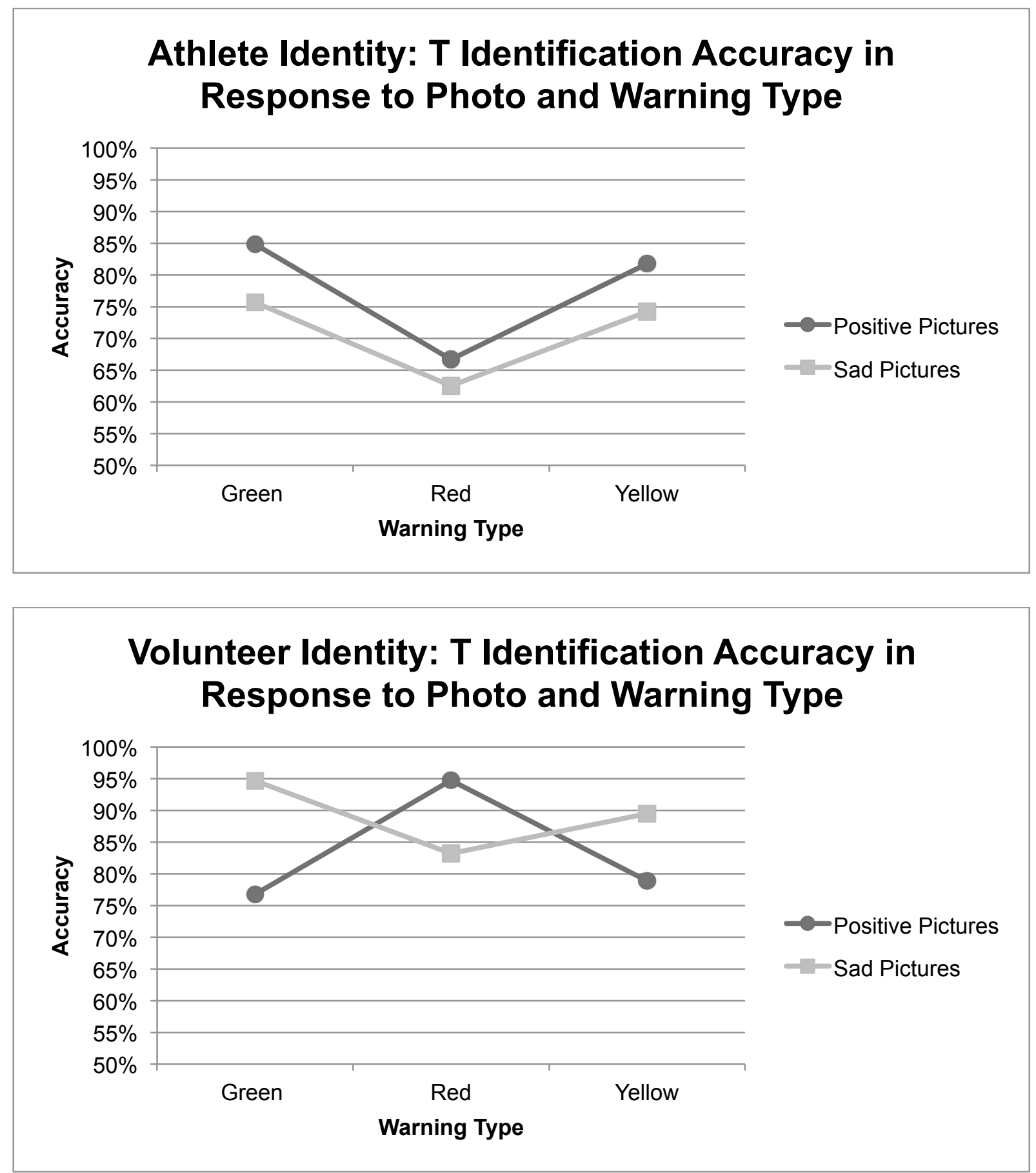

Note: There were 27 participants in the athlete condition and 25 in the volunteer condition. 